\title{
LOS GÉNEROS DEL DISCURSO COMO DISPOSITIVOS ENUNCIATIVOS DE LAS PRÁCTICAS SOCIALES: UNA MIRADA TEÓRICA Y PRÁCTICA
}

\author{
DISCOURSE GENRES AS ENUNCIATIVE DEVICES OF SOCIAL PRACTICES: A \\ THEORETICAL-PRACTICAL PERSPECTIVE
}

\author{
Adail Sobral \\ Universidade Federal do Rio Grande, Rio Grande, Rio Grande do Sul, Brasil \\ adail.sobral@gmail.com \\ Karina Giacomelli \\ Universidade Federal de Pelotas, Pelotas, Rio Grande do Sul, Brasil \\ karina.giacomelli@gmail.com
}

Resumen: Este artículo de carácter didáctico explora el concepto de género discursivo desde la perspectiva de su relación con las prácticas sociales y su potencial didáctico, presentándolos teórica y prácticamente, presentando incluso un análisis. El artículo se basa en la perspectiva de la Análisis Dialógica del Discurso (ADD) de Bajtín y el Círculo. Se trata de una perspectiva que considera tanto las estructuras lingüísticas y textuales cómo las huellas que, venidas de la situación de producción de sentidos, de la enunciación, son dejadas en el texto resultante de la actividad discursiva.

Palabras llave: Géneros; Prácticas Sociales; Dialogismo; Didáctica de Géneros

Abstract: This paper has a didactic purpose and explores the relations of speech genres to social practices and their potential as didactic devices, presenting them theoretically and providing an analysis. The paper is based on the perspective of Dialogical Discourse Analysis (ADD Análisis Dialógico del Discurso) by Bakhtin and the Circle. Such perspective considers both strictly linguistic and textual components of utterances and pragmatic discursive elements which come from the situation of sense production, i.e., from the context of enunciation, which imprints enunciation marks in texts resulting from discursive activity.

Keywords: Genre; Social Practices; Dialogism; Genre Education

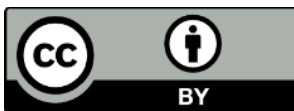




\section{INTRODUCCIÓN}

Según el Análisis Dialógico del Discurso, el centro de la comunicación es la direccionalidad (o, para otros, el enderezamiento), el direccionamiento por el hablante a un interlocutor. El sentido manifiesto en los enunciados adviene de la relación dialéctica entre los elementos de la lengua y aquellos que intervienen en la producción discursiva, las mediaciones entre lo real concreto y la producción de enunciados - en las condiciones específicas de interlocución, de enderezamiento del dicho al interlocutor, de la expresividad del locutor (su posición valorativa) e de la referencialidad (aquello de que habla él).

El Círculo de Bajtín considera la lengua per se un sistema, pero va más allá, pues todo dicho es más que la lengua, dado que revela la posición enunciativa, social e histórica, de los interlocutores. La interacción va más allá de la situación de decir, englobando la suma total de las relaciones sociales de cada sujeto involucrado. Para el Círculo, antes de pensar en decir algo, el sujeto ya está considerando el interlocutor a quién se dirige, a quién dirige su discurso.

Además, la lengua como sistema es neutra, pero los signos adquieren sentidos ideológicos diferentes cuando usados en la producción de enunciados. El contenido de la psique individual es considerado tan social como lo son los fenómenos ideológicos, aunque la individualidad sea un factor importante: somos todos seres sociales, pero cada uno de nosotros tiene un modo específico de serlo. Así, todos los productos ideológicos muestran tanto la individualidad como el estatuto social de sus creadores; implican tanto la objetivación social como la apropiación personal del mundo. Todos los signos adquieren, de esta manera, propiedades y atributos de fenómenos ideológicos, y todo lo que es ideológico posee valor semiótico (Voloshinov, 2009, passim).

El texto es parte del aparato técnico, de los recursos de realización de objetivos discursivos, parte del proceso de instauración de sentidos, que no es estrictamente textual, y va más allá de las significaciones cristalizadas en la lengua (lo que está en los diccionarios). El discurso es una unidad del nivel de las prácticas sociales en las cuales ocurren las relaciones de interlocución, base del proyecto enunciativo, el "querer decir" del locutor.

El género es una forma-contenido de recorte social e ideológico del mundo que emplea formas textuales, movilizándolas discursivamente con objetivos sociales e históricos nacidos en las esferas de actividad. Bajtín lo define como "tipos relativamente estables de enunciados" (Bajtín, 1998, p. 248), y Voloshinov como "formas y tipos de comunicación discursiva", géneros del habla (Voloshinov, 2009, p. 45), inseparablemente conectados a sus condiciones enunciativas concretas. Como dice Bajtín (1998, p. 248),

Cada enunciado separado es, por supuesto, individual, pero cada esfera del uso de la lengua elabora sus tipos relativamente estables de enunciados, a los que denominamos géneros discursivos (Bajtín, 1998, p. 248).

Destacamos que esos componentes no son categorías separables que se puedan utilizar para un análisis formal; se trata de elementos que definen el género.

Son propriedades indisociables de la totalidad del género el contenido temático, el estilo y la composición. En palabras de Bajtín (1998, p. 248):

Los tres momentos (...) - el contenido temático, el estilo y la composición - están vinculados indisolublemente en la totalidad del enunciado y se determinan, de un modo semejante, por la especificidad de una esfera dada de comunicación (Bajtín, 1998, p. 248)

Así es que: 
El Tema o contenido temático, que es diferente del tópico, presenta la posición de la que uno habla de los tópicos. Por ejemplo, las fábulas presentan una narrativa, con personajes, que es su tópico, y una máxima, que recurre a ese tópico. Pero su tema no es la narrativa misma, sino una regla moral que viene en la máxima, uno de los componentes de la fábula.

El Estilo es expresión de la comunicación discursiva específica del género (relaciones enunciativas) y expresión personal no subjetiva, porque enderezada a un destinatario en términos de su estatuto social relativamente al hablante. El estilo depende de la direccionalidad, de las relaciones del hablante con el destinatario al que se dirige el enunciado y, por lo tanto, del proyecto enunciativo configurado en la arquitectura (o forma arquitectónica) y en el tema o unidad temática.

La forma composicional o composición realiza la forma arquitectónica (organización valorativa del texto) y depende de ella, siendo la forma arquitectónica determinada por el proyecto enunciativo (el proyecto de decir o voluntad enunciativa) del locutor según las necesidades y posibilidades sociales de la comunicación.

Una decisión judicial en algunos países se puede escribir como un poema (composición), por ejemplo, pero debe obligatoriamente contener una fórmula jurídica (arquitectónica) que enmarca una decisión judicial, y no un poema. Y, en especial, sólo un juez la puede escribir. Un poema que representa una decisión judicial es sólo un poema; una decisión judicial escrita por un juez en la forma de un poema según las reglas judiciales es una decisión judicial. Son vitales la relación enunciativa hablante-destinatario, el estatuto social de hablante y destinatario en sus relaciones $\mathrm{y}$, especialmente, lo que el género realiza en su direccionalidad según su esfera de actividades: solicita, juzga, impone...

De este modo, los géneros son el resultado dinámico de una actividad autoral dialógica que moviliza el contenido [el objecto del discurso], el material [el lenguaje, formas de textualización etc.] y la forma [composicional y arquitectónica]; el tratamiento lingüístico y el enunciativo, el verbal y el extraverbal (Sobral, 2009, p. 120). Los géneros se vinculan a espacios sociales que forman su "esfera de actividad". Las esferas son campos de recorte socialhistórico-ideológico del mundo, es decir, de construcción de relaciones específicas entre sujetos a través de géneros (Sobral, 2009, p. 121).

La direccionalidad es lo que determina la selección del género del enunciado, de su tema, de procedimientos de estructuración y, finalmente, de los recursos lingüísticos vinculados al estilo del enunciado: "La selección de todos los medios lingüísticos se realiza por el hablante bajo una mayor o menor influencia del destinatario y de su respuesta prefigurada" (Bajtín, 1998, p. 270), es decir, el destinatario y su respuesta influencian los enunciados del locutor antes de que él hable. Su habla no es abstracta, sino concreta, dirigida a un destinatario que la altera.

Así, cuando habla, el locutor siempre toma en cuenta el fondo aperceptivo que posee su destinatario: hasta qué punto él conoce la situación, si posee o no conocimientos específicos de la esfera comunicativa cultural, cuáles son sus opiniones y convicciones, cuáles son sus prejuicios (desde mi punto de vista), cuáles son sus simpatías y antipatía - todos elementos que van a determinar la comprensión activa con que él reaccionará al enunciado, y que el locutor prefigura. El fondo aperceptivo afecta las maneras de producción de enunciados, dirigidos a destinarios determinados, de parte del hablante. Hay géneros en los que la influencia de la respuesta prefigurada del destinatario es mayor y otras en las que es menor.

\section{GÉNEROS Y PRÁCTICAS SOCIALES}


Antes que todo, hay que decir que "lengua" en la ADD se refiere al sistema de la lengua, y "lenguaje", que es mi foco, al sistema de los usos de la lengua, que la incorpora y va necesariamente más allá de ella. La lengua es el lugar de las significaciones del sistema y, el lenguaje, el lugar de los sentidos, que son siempre contextualmente constituidos. No hay sentido fuera de contexto, aunque sí haya significaciones, aquellas que están en los diccionarios. Las significaciones son de la lengua; el sentido, del lenguaje. Hay así un sistema formal de reglas (lengua) y un sistema flexible de usos (el lenguaje), que se configura como la movilización de la lengua por la enunciación en el intercambio verbal.

Según la mirada bajtiniana, toda práctica humana es constitutivamente social; no hay acto humano no social, y las identidades personales son ellas mismas construcciones sociales continuas que dependen de las interacciones. Cada sujeto humano realiza a su manera sus actos, pero lo hace siempre relacionalmente, en la sociedad y la historia. Así es que el soliloquio se realiza en el interior del sujeto, y se realiza de una manera propria de cada sujeto, pero es social, porque, aunque no haya un interlocutor físicamente presente, o un interlocutor supuesto especifico, la adquisición del lenguaje ocurre en las interacciones, y por eso el otro siempre está presente.

No hay lengua privada: hay siempre que hablar de modos que algún interlocutor, real o presunto, comprenda. La interacción según Bajtín ocurre con o sin la presencia física del interlocutor, y oralmente o en la escrita. Práctica social es así toda práctica en las que sujetos humanos están actuando. Las prácticas individuales humanas son todas prácticas sociales porque los sujetos humanos viven inmersos en interacciones.

Bajtín, a partir de esa proposición, presenta lo que denominó una concepción constitutiva de comunidad: más allá de las interacciones específicas, lo que dialoga es toda la sociedad, configurada en la suma total de las interacciones en las que participan los sujetos humanos. La comunidad constitutiva es más que interactiva en sentido estricto, y no se asocia necesariamente con un lugar físico en el que los sujetos se relacionan. Es decir, las relaciones dialógicas no suponen, como para manifestarse, la presencia física en un mismo local de los interlocutores, pero el contacto en general, que es marcado por la responsividad.

Las redes sociales, hoy día, son en cierta manera las comunidades sin local por excelencia. Entiendo por redes sociales las redes que se forman em los sitios de redes sociales, como Facebook, que son plataformas de redes; estas se forman por diferentes relaciones entre las personas. P0ersonas de países, géneros sociales y profesiones distintas etc., a partir de intereses comunes, constituyen esas redes. Ellas redes son por sí decir la materialización de lo que Bajtín $(1998,1989)$ afirma acerca las relaciones entre enunciados y sujetos, su dialogismo generalizado, que transciende épocas y lugares, y se configura en la permanencia de los enunciados en sus efectos: los enunciados jamás desaparecen, porque sus sentidos se recuperan, se renuevan etc. en nuevos enunciados.

La comunidad constitutiva se organiza en términos de lenguaje según las esferas de actividad, en donde hay prácticas sociales de producción, circulación y recepción de discursos, prácticas que establecen la estabilidad relativa de los géneros según las necesidades de comunicación de los sujetos. Es vital aquí decir que el texto es el aparato técnico de los géneros y no géneros per se. Los textos movilizados por los géneros se definen a través de la forma de composición, el tema y el estilo, los recursos técnicos que sirven a los proyectos enunciativos de los locutores.

Esos recursos no sirven a un análisis de géneros porque los constituyen conjuntamente, pero son indisociables y son considerados en los análisis. El proyecto enunciativo se vincula con una determinada arquitectónica o manera específica como el locutor organiza sus enunciados utilizando los recursos técnicos, pero a partir de las condiciones sociales en las que se enuncia. 
Los géneros son, por lo tanto, formas de interlocución vinculadas a esferas de actividad, en donde hay prácticas sociales de producción, circulación y recepción de discursos, que se manifiestan en textos movilizados por géneros. Los géneros se definen más ampliamente en términos de referencialidad, expresividad y direccionamiento, es decir, a partir del perfil presunto de los interlocutores (direccionamiento), el locutor habla de un objeto del mundo (referencialidad) desde un punto de vista valorativo (expresividad) que es afectado por sus relaciones específicas con los interlocutores a los que dirige su discurso (profesor, alumno, jefe...).

Son prácticas significativas que unen, a través de las relaciones enunciativas que establece, en el contexto de las esferas de actividad, el plano textual al plano contextual. El género lo hace sin que un contexto dado equivalga necesariamente a un texto dado o que un contexto dado solo produzca un texto dado. Las diversas esferas de la actividad humana organizan el uso de la lengua. Este se lleva a cabo a través de enunciados concretos, que reflejan las condiciones específicas de cada esfera por su contenido temático, su estilo verbal y su composición y estructuración, que son, como señalamos, el aparato técnico de la realización de los géneros.

Cada esfera produce sus tipos específicos de género con un tipo de destinatario específico de los enunciados de ese género y es, repetimos, la adecuación a ese destinatario, con el que el sujeto interactúa, lo que hará que el locutor decida cómo va a movilizar tema, estilo y composición, según su proyecto enunciativo, para organizar lo que él pretende comunicar, presentando su valoración del objecto de sus enunciados, es decir, los géneros se basan en el enderezamiento (dirigirse al destinatario), la referencialidad (el objecto de que uno habla) y la expresividad (la valoración del locutor, su entonación valorativa).

El enunciado es la unidad real de la comunicación discursiva. Es enderezado por el locutor a su interlocutor real o presunto, presente o ausente con una dada valoración que afecta su objeto, su referente. Reflete y refracta el objecto del mondo de lo que habla según la posición relativa del locutor frente a su interlocutor en la sociedad y la historia.

En cuanto a su objecto (referencialidad), los enunciados presentan conclusividad. Esta deriva del carácter intencional de su autor: él quiere decir algo con un determinado proyecto. El autor del enunciado lo concluye cuando ha dicho todo lo que pretendía. La conclusividad no es totalmente libre, porque hay formas típicas, genéricas, de conclusividad, relativamente estables.

La expresividad se basa más directamente en la intencionalidad comunicativa del autor del enunciado. Se trata del punto de vista del autor sobre el objecto de su enunciado. Es eso la base de la idea del lenguaje como un espacio de lucha ideológica, manifiesta en la confrontación de cosmovisiones.

La experiencia del sujeto con el lenguaje, que es personal en cuanto a la realización, pero siempre colectiva en cuanto a las posibilidades expresivas, implica por lo tanto la movilización de diferentes saberes y experiencias enunciativas, en términos de adaptación a los interlocutores, de variantes y registros que se pueden usar, valoraciones posibles, especificidades de la sociedad, su momento histórico, especificidades de la interacción, la relación específica entre los participantes, entre otros factores. Cuanto más grande la experiencia interaccional del sujeto, mayor será su repertorio de recursos expresivos (incluyendo su movilización de los géneros) y su capacidad de movilización contextualmente sensible de recursos discursivos.

El lenguaje uno aprende en las prácticas sociales, en las que uno forma continuamente su identidad. Uno viene a ser sujeto en contacto con otros sujetos y aprende el lenguaje en ese contacto, y uno es también el otro del otro, realizando siempre más lo que uno puede ser, relacionalmente, y no en insularidad. Por lo tanto, cuanto más grande el acceso de los sujetos a 
las diferentes variedades de la lengua, a las diversificadas prácticas en las que el lenguaje está presente, situaciones y prácticas enunciativas, etc. mayor será su repertorio discursivo-genérico (o enunciativo) y su capacidad de interacción y, por lo tanto, más grande sus condiciones de realizar su identidad y su ciudadanía.

Hablar de repertorios enunciativos es reconocer la importancia de la capacidad de usar el lenguaje de varias maneras culturalmente aceptadas: el foco sale de la estructura de la lengua y pasa a la capacidad de participación eficaz de los hablantes en intercambios verbales. Las lenguas son esencialmente multidiscursivas, o alter-discursivas, en cierto modo radicalmente: el discurso de cada sujeto es ya, antes que él hable, una combinación de palabras de otros y palabras suyas según las exigencias del contexto de habla.

El discurso de todo sujeto tiene que ocurrir necesariamente en términos de los géneros del discurso, marcados por proyectos enunciativos y por las restricciones de las prácticas sociales en las que existen. Y su desarrollo siempre depende del interlocutor a quien el sujeto se dirige, aunque ni uno ni el otro sea determinante. El elemento primordial son las relaciones y no los términos, como ha dicho Hjelmslev.

No hay universales genéricos ni géneros universales, a pesar de ciertas semejanzas de situaciones enunciativas en distintos contextos y distintas lenguas. Las características sociales e históricas de las lenguas se manifiestan em el lenguaje. Claro que, sin las semejanzas entre las lenguas, sería imposible aprender o hablar otro idioma, o traducir, porque las diferencias serían irreconciliables.

Por lo tanto, las lenguas son sistemas complejos constituidos por la integración dinámica del sistema de reglas de la lengua y el sistema de uso del lenguaje; el sistema de reglas se refiere, naturalmente, al aspecto lingüístico estricto, mientras el sistema de uso, menos estrictamente sistemático, pero no menos organizado, es el plano de las diferentes situaciones enunciativas de las cuales los sujetos pueden participar. Las situaciones enunciativas son parte de las prácticas sociales, y estas son parte de las esferas de actividad, las cuales dependen de la configuración de cada sociedad.

\section{GÉNEROS COMO DISPOSITIVOS ENUNCIATIVOS}

Percibimos que, según las proposiciones de Bajtín, se adquiere la lengua a través de los géneros, y estos constituyen el nivel discursivo de la variación lingüística más general. Ese es un nivel enunciativo-discursivo, porque el dialogismo incluye tanto discurso como enunciación, al contrario de algunas teorías de la enunciación o del discurso. En ese plano, tanto la estabilidad como la variación del plano de la lengua se convierten en objetos apropiados por el plano del lenguaje, de donde viene el sentido. Los géneros son así un espacio de organización social de los intercambios verbales y de libertad relativa de los sujetos interlocutores.

Los géneros presentan aspectos repetibles e irrepetibles; aquellos se vinculan con su estabilidad y estos con su relatividad, y la interacción entre esos aspectos les confiere su dinamicidad. Son, en consecuencia, dispositivos enunciativos de las prácticas sociales, presentando una dimensión textual, una dimensión discursiva y una dimensión social e histórica situada. Ellos tanto presentan el mundo, reflectándolo y refractándolo, cómo lo construyen simbólicamente, es decir, su presentación va más allá de la representación. Son, así, una presentación valorada.

¿Qué significa decir que los géneros son dispositivos enunciativos de las prácticas sociales? Significa en términos generales que, dada su especificidad, enseñamos los géneros, pero no los trasmitimos, porque ellos son dinámicos y no son reducibles a fórmulas.

Se emplea "dispositivo" para describirlos porque ellos no son solamente formas, ni solo contenido, ni apenas lugar de las significaciones, ni solo de los sentidos. Ellos integran el 
sistema de la lengua a los usos enunciativos. Se trata de entidades que reúnen forma y contenido, texto y contexto, sistema y uso, y organizan las interacciones, permitiendo a los hablantes el entendimiento entre si sin la reinvención, a cada momento, de maneras de hacerlo. Los géneros organizan las interacciones entre los hablantes sin privarlos de la creatividad, de la apropiación de los recursos expresivos de la lengua a su manera, según sus interlocutores específicos y su intencionalidad posible. Dispositivo enunciativo, en consecuencia, congrega el conjunto de procedimientos mediante los cuales uno enuncia a través los géneros.

En su condición de dispositivo enunciativo, los géneros merecen un tratamiento que integre más productivamente el textual al discursivo, buscando identificar, en los textos, como el "extratextual" es incorporado al texto, es decir, como el contexto es intratextualizado (convertido en parte intrínseca del texto).

\section{LOS ELEMENTOS CONSTITUTIVOS DE LOS GÉNEROS}

Los textos, siempre organizados según un género, no existen sin la producción (el locutor) e y la recepción (el interlocutor). Esos tres elementos son esenciales como para comprender los géneros. Se consideran las situaciones enunciativas (tiempo, espacio y ambiente) presentes en las prácticas sociales (formas de organizar las relaciones e interacciones humanas) según las esferas de actividad (los campos de actividad: escolar, mediático, etc.) dónde hay la producción, circulación y recepción de discursos, configurados enunciativamente en géneros.

El centro de todo es el enderezamiento, la manera como el locutor se dirige al interlocutor. El enderezamiento es el índice más claro de las expectativas del locutor, de su proyecto enunciativo e de la forma arquitectónica empleada, frente a su interlocutor. El proyecto enunciativo es proyecto de decir, voluntad enunciativa, lo que el locutor quiere que el interlocutor comprenda y haga. La forma arquitectónica recubre la manera como los recursos formales de la lengua son trasformados en componentes del discurso según ese proyecto. Se puede decir "Qué calor, ¿no?" con más de un proyecto. Por ejemplo, puede ser un simple comentario o una manera de hacer alguien descerrar la ventana. El contexto de las relaciones entre locutor e interlocutor va a definir qué es pretendido. En la escrita, se puede presentar el perfil de un personaje político, por ejemplo, tanto para congratular cuanto para denunciar.

En el análisis, uno considera la esfera de actividad, la práctica social y las situaciones enunciativas del género producido, y examina las tres dimensiones de los géneros (genérica, discursiva y textual) y los tres aspectos definidores de los géneros: el aspecto referencial (de qué se habla), el aspecto expresivo (de qué perspectiva se habla) y el aspecto de direccionamiento (a quien uno se dirige). Tema, forma de composición y estilo, componentes lingüísticos de los géneros, se definen a partir de esas tres dimensiones y de los tres aspectos. Se trata de componentes integrados de los géneros, y no categorías de análisis.

\section{Niveles de Análisis}

Desde esa perspectiva de análisis, hay dos niveles articulados: el nivel "macro", el de la inserción social del género; e el nivel “micro', el de las formas típicas de organización textual del género en lo que se inserta el texto.

Los elementos del nivel "macro" son:

- La esfera de actividad del género, considerando lo que crea, en el contexto de la esfera, las características del género;

- Las discursividades que se muestran y las textualidades más o menos típicas del género; 
- El contexto de enunciación del género en términos de su producción, circulación y recepción.

Los elementos del nivel micro son:

- Los aspectos textuales que permite caracterizar los textos como miembros de un género, y sus especificidades como género;

- Las estrategias de autoformación y de interformación de los textos según los principios del género;

- Los modos específicos de creación por el género de interacciones entre el enunciador y su interlocutor;

- Las maneras específicas a que recurre el enunciador para llevar el interlocutor a aceptar las "teses" defendidas en su proyecto enunciativo en el contexto del género.

\section{La Práctica de Análisis}

¿Pero cómo se procede en el análisis basado en esos parámetros enunciativos, discursivos y textuales?

Uno debe identificar en el texto que va a ser analizado, y en su contexto, "respuestas' para las siguientes "cuestiones" - es decir, buscar datos del texto e del contexto que permitan identificar los componentes de los géneros, sin fragmentar el texto ni convertir esos elementos em categorías, lo que ellos no son; se trata de parámetros:

- ¿Quiénes son socialmente el locutor y el interlocutor típicos de los enunciados de los géneros analizados: ¿quiénes los producen y quiénes son sus destinatarios típicos? No se trata solamente del locutor persona identificable del texto sino también su lugar social. Por ejemplo: jefe y empleado

- ¿Dónde circulan los géneros analizados: dónde los locutores los presentan y donde los lectores los leen? Por ejemplo: una empresa

- ¿Qué pretenden los locutores realizar con los géneros analizados, es decir: ¿qué acto el género realiza (ordenar, solicitar)?

- ¿Qué esperan de los interlocutores ¿qué deben esos hacer frente al enunciado (obedecer, cumplir el pedido)? Por ejemplo, que el empleado envíe un mensaje; que él explique algo, que se disculpe...

- ¿Cómo se dirigen a los interlocutores, es decir, cuál el tipo de interactuación que se proponen a establecer? Por ejemplo, el jefe habla al empleado con autoridad, con deferencia, autoritariamente...

- ¿Qué recursos textuales y lingüísticos movilizan, es decir, ¿cuál es la materialidad que realiza el género y cómo el texto es organizado? Por ejemplo, con un imperativo: “ ¡Envía un mensaje urgentemente al director de x!” o un interrogativo ¿"Podrías enviar un mensaje urgentemente al director de x?" o un imperativo atenuado " $P$ Por favor, envía un mensaje urgentemente al director de $\mathrm{x}$ !".

- ¿Qué efectos esperan producir con esto? ¿Qué esperan los locutores de los interlocutores? Por ejemplo, que el empleado envíe inmediatamente un mensaje, que él se disculpe por no haber enviado ese mensaje anteriormente... Si se considera el enderezamiento y las formas textuales, palabras escogidas etc., ¿el locutor espera imponerse al interlocutor, conmoverlo como para que cumpla su pedido?

\section{DESCRIIPCIÓN, ANÁLISIS, INTERPRETACIÓN: LAS ETAPAS DE ANÁLISIS}


Esas etapas de análisis fueron desarrolladas por Beth Brait en sus clases en el Programa de Lingüística Aplicada y Estudios de Lenguaje de PUC-SP y por ella presentadas en los estudios doctorales de Adail Sobral (concluidos en 2006), de los que ella fue directora. Aunque la autora no los ha publicado, ella ha permitido a Sobral usarlos y testarlos en su tesis (Sobral, 2006). En la tesis, Sobral las desarrolló según sus necesidades y las fue resignificando. Las presentamos aquí como están en el texto (Sobral \& Giacomelli, 2016, p. 1093):

Cuando describe, el analista examina la materialidad de su objecto, compuesto de una parte lingüística y una parte enunciativa integradas; en ese momento, él ve su objecto. Cuando analiza, adquiere conocimiento sobre las relaciones entre los dos partes (lengua y enunciación) en el enunciado considerado en términos de la intencionalidad del locutor frente a su(s) interlocutor(es). Por fin, cuando interpreta, él integra todos esos dados - la materialidad de la lengua y los elementos del acto de enunciación em sus relaciones en un dado contexto que implica tiempo, espacio e interlocutores - y, a partir de eso, procura identificar los sentidos creados (Sobral \& Giacomelli, 2016, p. 1093). ${ }^{1}$

En realidad, se puede hacer las tres etapas tanto en secuencia como simplemente considerando las características materiales y enunciativas (descripción) del objeto, verificando cómo él organiza los elementos materiales y enunciativos identificados (análisis) e interpretando los sentidos creados mediante la integración entre la materialidad textual y el acto enunciativo que produce el género (interpretación) - es decir, la interpretación va siempre considerar la instauración de sentidos basada en las características lingüísticas (la lengua como sistema) e lenguajeras (el lenguaje como manifiesta en la enunciación) del objeto.

Lo que se pretende es hacer que la interpretación no sea una opinión o sensación del analista, pero esté fundada en una consideración cuidadosa de la materialidad y del contexto de enunciación, que el analista demuestre lo que dice en su interpretación. No se trata de algo exhaustivo, pero de una actitud que busca siempre, frente al texto, establecer quién se dirige a quién dónde cuando cómo para qué, porque los géneros son dispositivos enunciativos que organizan las interacciones movilizando esencialmente esos aspectos. Los géneros son más que forma y más que contenido, maneras de hablar organizadamente sobre el mondo que nos permiten no reinventar a cada enunciación una manera de enunciar pero que también nos conceden libertad en medio de las restricciones.

\section{Un ejemplo de análisis según las etapas de descripción, análisis, interpretación}

Vamos a presentar aquí, con adaptaciones, un análisis (cf., Sobral \& Giacomelli, 2016, p. 1086-1087) acerca la fábula "O lobo e o Cordeiro". "El lobo y el cordero", en español, es el mismo género fábula, pero adaptamos el análisis porque su textualización es distinta. Es decir, los textos en las dos lenguas son ejemplares del mismo género, aunque presenten diferencias textuales.

\section{El lobo y el cordero}

\footnotetext{
${ }^{1}$ En el original: "Ao descrever, o analista examina a materialidade de seu objeto, composto por uma parte linguística e uma parte enunciativa integradas; nesse passo, ele vê seu objeto. Ao analisar, ele adquire conhecimento sobre as relações entre as duas partes (língua e enunciação) no enunciado considerado em termos da intencionalidade do locutor diante de seu(s) interlocutor(es). Por fim, ao interpretar, ele reúne todos esses dados - a materialidade da língua e os elementos do ato de enunciação em suas relações num dado contexto envolvendo um tempo, um espaço e interlocutores - e, a partir disso, procura identificar os sentidos criados."
} 
Un lobo y un cordero cada uno por su lado, fueron a un río a beber agua para calmar su sed.

El lobo estaba bebiendo agua en la parte de arriba del rio, mientras que el cordero bebía agua más abajo.

El lobo, buscando pretextos para atacar al cordero comienza a decirle lo siguiente, ¿Por qué me enturbias el agua mientras yo bebo?

El cordero responde, preguntándole al lobo, que como él le puede empañar el agua si está bebiendo en la parte baja del rio.

El lobo, no entrando en razón y no escuchando al cordero, le acusa diciéndole que está blasfemando, el cordero en su defensa alega que no ha blasfemado, y que solo quiere beber agua.

Pero el lobo, buscando más pretextos para atacar y comerse al cordero, le acusa diciéndole que su padre hace seis meses atrás le había ofendido.

El pobre cordero le dice que el en ese tiempo todavía ni había nacido.

Eso no importa - dice el lobo - pagaras la ofensa de tu padre con tu vida, y tras decir eso, el lobo se lanza sobre el cordero y lo devora.

Y es que de poco sirve razonar, que la razón del más fuerte siempre es la mejor.

El texto de la fábula empieza con una narrativa, que es su tópico, o asunto, pero termina con una lección de moral (moraleja), un enunciado que resume la historia e indica su tema, es decir aquello de lo que se desea hablar con la historia, más allá del texto de la narrativa. El tópico de la a fábula sirve para ilustrar una circunstancia a la que se aplica indirectamente la lección de moral (moraleja). El texto presenta la narración de una interacción entre un lobo y un cordero que es trágica para este. Nuestro conocimiento del mundo nos dice que lobos y corderos no hablan.

Entretanto, el género utiliza la llamada personificación, que permite presentar un lobo y un cordero en una charla. Por otro lado, no es novedad que lobos, animales predadores, maten corderos. Así, esa narrativa per se solo es relevante porque es parte de una fábula, constituye, combinada al segmento de la lección de moral (moraleja), el género fábula.

Hay un narrador, que, además de contar la historia y describir la situación, la valora con sus comentarios que presenta al lector pistas interpretativas ("buscando pretextos"; "responde, preguntándole al lobo"; "no entrando en razón"; " atacar y comerse al cordero", "El pobre cordero"; "en su defensa"; "solo quiere" etc.

Esas pistas indican al lector que el personaje lobo es malo y arbitrario y el personaje cordero bueno e inocente. Ellas preparan el lector para la parte final, la lección de moral (moraleja), la cual completa la unidad temática del texto, El texto no pretende hablar de los conflictos entre lobos y corderos, aunque ese sea su tópico. El autor habla de la violencia humana, de la ley del más fuerte, la arbitrariedad, del facto de que poco sirve razonar cuando el otro es más fuerte, violento y arbitrario.

Todas las fábulas presentan enunciativamente, con expresividad, un juicio moral, aunque sus maneras específicas de hacerlo (forma de composición: narrativa sin diálogos o con diálogos etc.; tópico: lobo. cordero, león, elefante etc.) varían de época para época, de autor para autor (que tienen sus estilos), de país para país, y hay incluso versiones distintas en un mismo país.

La relación enunciativa de una fábula es la relación entre un locutor habilitado para darle lecciones de moral a un lector a quienes el pensador se dirige para instruir: la moraleja (que nos recuerda de las afirmaciones conocidas como máximas) es un enseñamiento de una autoridad a non-autoridades. Además, el locutor utiliza una historia simple porque sus 
interlocutores constituyen un público que según el locutor necesita de la historia como para comprender la moraleja.

La narrativa es una especie de ilustración de la lección de moral. Es una relación asimétrica. Es a partir de esa asimetría que el locutor elije la forma de composición y la realiza, con su estilo, como para desarrollar su tema a partir de su tópico, realizando así su proyecto enunciativo.

Como se puede percibir, describimos los componentes y partes del texto de la fábula, analizamos sus elementos extralingüísticos y la posición enunciativa del locutor e del destinatario, y, por fin, interpretamos el texto basados en los dados de las etapas precedentes, que fueran integrados. No es necesario, como lo demostramos, separar descripción, análisis e interpretación, aunque uno lo puede y lo haga. Lo que importa es realizar las operaciones analíticas que las tres etapas, o procedimientos, indican como para examinar la unidad del texto.

\section{6 ¿GÉNEROS EN LA ESCUELA PARA QUÉ? EN BUSCA DE CONCLUSIONES}

¿Cómo se distingue el trabajo en clase con géneros y el trabajo tradicional, que utiliza solamente textos en cuanto materialidad de significación inmanente?

Cuando se trabaja con géneros en la escuela, se dispone de un valioso dispositivo enunciativo como para desarrollar inúmeras actividades de conocimiento y de actuación tanto de la lengua-sistema como del lenguaje-acto, tanto en la recepción de textos como en su producción y circulación.

Pero se necesita cuidado como para no deturpar los géneros, transformándolos en objectos estáticos o formas etc.

Sobral (2011, p. 42), hablando de la transposición didáctica respecto a los géneros, dice:

(...) todo texto, parte de algún género, cuando sufre la transposición didáctica pierde necesariamente algunas características e adquiere nuevas, y eso requiere el empleo de filtros que lo mantengan como tal e reconozcan su inevitable alteración en el ambiente escolar, que no es el ambiente típico de varios géneros o que ofrece sus propias versiones de géneros que se asemejan a otros, pero no son los mismos. Así, la transposición didáctica, aunque común e necesaria, siempre implica el dilema de deturpar aquello que pretende examinar em términos de las prácticas de que nasce, porque sus ojos son los ojos de sus características, y non de otras (Sobral, 2011, p. $42)^{2}$

Así es que, como para evitar deturpaciones, se exploran los siguientes elementos:

1. La condición de los géneros de maneras de organizar las interacciones entre las personas según las necesidades de comunicación de las esferas de actividad, lo que va más allá del texto.

2. El uso por los géneros de textos y formas textuales diversas para la comunicación, según el contexto de su empleo.

\footnotetext{
${ }^{2}$ En el original: “(...) todo texto, parte de algum gênero, ao passar pela transposição didática perde necessariamente certas características e adquire novas, o que requer o emprego de filtros que o mantenham como tal e reconheçam sua inevitável alteração pelo ambiente escolar, que não é o ambiente típico de vários gêneros ou oferece suas próprias versões de gêneros que se assemelham a outros, mas não são os mesmos. Assim, a transposição didática, ainda que corriqueira e necessária, está sempre às voltas com o dilema de deturpar aquilo que pretende examinar nos termos das práticas de que nasce, já que seus olhos são os de suas características, não de outras."
} 

movilizarlas.

Eso demuestra que non son formas o secuencias textuales sino maneras de

3. Las características de las personas que enderezan otras personas de promedio los géneros: ¿quién puede decir que a quién? ¿dónde? ¿cuándo ¿cómo? ¿para qué?

Los géneros sirven para que ellas interactúen según las necesidades suyas y las imposiciones de los contextos, siempre más allá del texto.

4. El facto de que los géneros se producen en contextos específicos para realizar objetivos específicos de los interlocutores según restricciones sociales, pero con relativa libertad. Se trata de su estabilidad relativa.

¡Por lo tanto, cuándo el profesor trabaja con géneros en clase, los alumnos aprenden que el sentido del lenguaje va siempre más allá del texto, aunque no se pueda prescindir de ello! Parodiando Greimas, quien dijo que "fuera del texto no hay salvación", dijimos que fuera del género no hay texto ni, por lo tanto, salvación.

\section{REFERENCIAS}

Bajtín, M. M. (1998). Estética de la creación verbal. Traducción Tatiana Bubnova. $8^{\mathrm{a}}$ ed. Buenos Aires: Siglo Veintiuno.

Bajtín, M. M. (1989). Teoría y Estética de la Novela: Trabajos de investigación. Traducción Helena S. Kriukova y Vicente Cazcarra. Madri: Taurus.

Sobral, A. (2006). Elementos sobre a formação de gêneros discursivos: a fase "parasitária" de uma vertente do gênero de auto-ajuda. Tese de Doutorado. PUC/SP.

Sobral, A. (2009). Do dialogismo ao gênero: as bases do pensamento do Círculo de Bakhtin. Campinas: Mercado de Letras.

Sobral, A. (2011). Gêneros discursivos, posição enunciativa e dilemas da transposição didática: novas reflexões. Letras de Hoje (46)1, p. 37-45.

Sobral, A., \& Giacomelli, K. (2016). Observações didáticas sobre a análise dialógica do discurso - ADD. Domínios de Lingu@Gem (10), p. 1076-1094.

Voloshinov, V. N. (2009). El Marxismo y la filosofía del lenguaje. Traducción Tatiana Bubnova. Buenos Aires: Ediciones Godot Argentina.

Recebido em: 13 de abril de 2020

Aceito em: 20 de maio de 2020

Publicado em Setembro de 2020 